\title{
Exposure to moderate air pollution and associations with lung function at school-age: A birth cohort study
}

\author{
Jakob Usemann ${ }^{\mathrm{a}, \mathrm{b}, 1}$, Fabienne Decrue ${ }^{\mathrm{a}, 1}$, Insa Korten ${ }^{\mathrm{a}, \mathrm{b}}$, Elena Proietti ${ }^{\mathrm{a}, \mathrm{b}}$, Olga Gorlanova ${ }^{\mathrm{a}}$, \\ Danielle Vienneau ${ }^{\mathrm{c}, \mathrm{d}}$, Oliver Fuchs ${ }^{\mathrm{b}}$, Philipp Latzin ${ }^{\mathrm{b}}$, Martin Röösli ${ }^{\mathrm{c}, \mathrm{d}}$, Urs Frey ${ }^{\mathrm{a}, *}$, on behalf of the \\ BILD study group ${ }^{2}$
}

${ }^{a}$ University of Basel Children's Hospital (UKBB), Spitalstrasse 33, 4056 Basel, Switzerland

${ }^{\mathrm{b}}$ Pediatric Respiratory Medicine, Department of Pediatrics, Inselspital, Bern University Hospital, Freiburgstrasse 15, 3010 Bern, Switzerland

${ }^{\mathrm{c}}$ Swiss Tropical and Public Health Institute Basel, Socinstrasse 57, 4051 Basel, Switzerland

${ }^{\mathrm{d}}$ University of Basel, Petersplatz 1, 4001 Basel, Switzerland

\section{A R T I C L E I N F O}

Handling Editor: Dr. Xavier Querol

Keywords:

Air pollution

Infant

Cohort

Prospective

Lung function

School-age

\begin{abstract}
A B S T R A C T
Background: Adverse effects of higher air pollution levels before and after birth on subsequent lung function are often reported in the literature. We assessed whether low-to-moderate levels of air pollution during preschoolage impact upon lung function at school-age.

Methods: In a prospective birth cohort of 304 healthy term-born infants, $232(79 \%)$ completed lung function at follow-up at six years. Using spatial-temporal models, levels of individual air pollution (nitrogen dioxide $\left(\mathrm{NO}_{2}\right)$ and ozone $\left(\mathrm{O}_{3}\right)$, particulate matter with a diameter $\left.<10 \mu \mathrm{m}\left(\mathrm{PM}_{10}\right)\right)$ were estimated for the time windows pregnancy, first up to the sixth year of life separately, and birth until follow-up at six years. Time window means were compared to World Health Organization (WHO) guideline limits. Associations of exposure windows with spirometry and body plethysmography indices were analyzed using regression models, adjusting for potential confounders. For subgroup analysis, air pollution exposure was categorized into quartiles (four groups of 52 children).

Results: Mean $\mathrm{NO}_{2}$ level from birth until follow-up was [mean (range)] [11.8 (4.9 to $\left.35.9 \mu \mathrm{g} / \mathrm{m}^{3}\right)$ ], which is almost 4-times lower than the WHO suggested limit of $40 \mu \mathrm{g} / \mathrm{m}^{3}$. In the whole population, increased air pollution levels from birth until follow-up were associated with reduced lung function at six years. In the subgroup analysis, the 52 children exposed to $\mathrm{NO}_{2}$ levels from the highest quartile during pregnancy, the first and second years of life and from birth until follow-up, had a significant decrease in forced expiratory volume in $1 \mathrm{~s}\left(\mathrm{FEV}_{1}\right)$. Per interquartile range increase of $\mathrm{NO}_{2}, \mathrm{FEV}_{1}$ decreased by [z-score change $(95 \%$ confidence interval)] $[-1.07$ $(-1.67$ to -0.47$)]$, [ $-1.02(-1.66$ to -0.39$)],[-0.51(-0.86$ to -0.17$)]$ and $[-0.80(-1.33$ to -0.27$)]$, respectively. Air pollution exposure during pregnancy and childhood resulted in a non-significant decrease in lung volume at six years, as assessed by functional residual capacity measured by body plethysmography (FRC pleth $_{\text {). }}$.

Conclusion: Our results suggest that exposure to higher $\mathrm{NO}_{2}$ levels, which are still much lower than WHO guideline limits, especially during the sensitive period of early lung development, may be associated with reduced lung function at school-age. These findings support the concept of age and dose-dependent pollution effects on lung function in healthy school-aged children and underline the importance of pollution reduction measures.
\end{abstract}

\footnotetext{
* Corresponding author.

E-mail address: urs.frey@ukbb.ch (U. Frey).

1 These authors contributed equally.

${ }^{2}$ Basel Bern Infant Lung Development (BILD) cohort, current study group: Pinelopi Anagnostopoulou, MD, Bern; Rhea Appenzeller, MD, Basel; Fabienne Decrue,

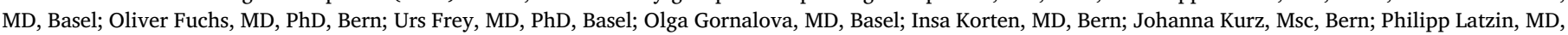
PhD, Bern; Elena Proietti, MD, PhD, Basel; Anne Schmidt, MD, PhD, London; Andràs Soti, MD, Bern; Jakob Usemann, MD, PhD, Basel.
} 


\section{Introduction}

Adverse effects of air pollution on lung function in newborns (Latzin et al., 2009), during childhood (Bougas and Ranciere, 2018; Jedrychowski et al., 2010; Jedrychowski et al., 2015; Morales et al., 2015; Mortimer et al., 2008; Schultz et al., 2012) and adolescence (Schultz et al., 2016) have been reported. Different exposure windows during lung development have been investigated in order to identify a critical time frame. While some studies reported small-scale associations between higher air pollution exposure during pregnancy and reduced lung function at school-age (Bougas and Ranciere, 2018; Jedrychowski et al., 2010; Jedrychowski et al., 2015; Morales et al., 2015; Mortimer et al., 2008), other studies reported that exposure during infancy, but not pregnancy, was associated with reduced lung function at school-age (Schultz et al., 2012; Schultz et al., 2016). These conflicting findings suggest that different exposure windows during lung development may differently affect lung function. Effects may be dose and age dependent and prospective studies with continuous exposure assessment, measuring from pregnancy onward, might help to identify sensitive exposure windows.

Few studies continuously assessed air pollution before and after birth and studied its association with lung function at a mean age of 4.5 (Morales et al., 2015) and 6-11 years (Mortimer et al., 2008; Korten et al., 2017). Importantly, pollution levels in these studies were high. While there is a clear association between higher air pollution and subsequent reduced lung function (Morales et al., 2015; Mortimer et al., 2008), adverse effects of moderate air pollution in adults are recognized (Vodonos et al., 2018); however, in primarily healthy children are less understood. Studying the latter is particularly important given recent attempts to decrease air pollution in some countries (e.g. Switzerland) (Bundesamt für Umwelt (BAFU) Schweiz, 2018), which may result in less severe adverse effects on lung development.

Our research group previously measured lung volume in 5 week-old unsedated infants using multiple breath washout (Latzin et al., 2009), a method feasible for measuring functional residual capacity (FRC) in newborns (Usemann et al., 2017). We found a negative association between nitrogen dioxide $\left(\mathrm{NO}_{2}\right)$ during pregnancy and FRC in newborns (Latzin et al., 2009), suggesting deleterious effects of air pollution on functional lung volumes in early infancy. However, little is known about critical exposure windows during early childhood and their impact on lung volume during childhood, and particularly effects of lowlevel air pollution exposure below the World Health Organization (WHO) guideline limits $\left(\mathrm{NO}_{2} 40 \mu \mathrm{g} / \mathrm{m}^{3}\right.$ ) (World Health Organization (WHO), 2018).

The aim of this study was, to determine within a prospective birth cohort of unselected infants, if low-to-moderate pollution levels were associated with changes in airway obstruction and lung volume at six years of age. For a detailed exposure assessment, we assessed individual air pollution levels from pregnancy until school-age, enabling us to assess the dose-dependent effect of different exposure windows, but particularly in very early life during suspected windows of susceptibility on subsequent lung function (Morales et al., 2015; Schultz et al., 2012).

\section{Methods}

\subsection{Study design and subjects}

The prospective Basel-Bern Infant Lung Development (BILD) birth cohort study (https://www.bild-cohort.ch/) comprises a group of unselected, healthy neonates recruited antenatally since 2002 in the region of Bern, Switzerland (Fuchs et al., 2012). Exclusion criteria for the study were preterm delivery $(<37$ weeks) and significant perinatal disease, including respiratory distress and later diagnosis of chronic respiratory disease. Potential risk factors were assessed by interviews using standardized questionnaires. Children underwent a lung function measurement at follow-up at six years. The Ethics Committee of the Region of Bern approved the study and written consent was obtained at enrolment.

\subsection{Air pollution exposure during pregnancy and childhood}

Air pollution data included daily mean levels of nitrogen dioxide $\left(\mathrm{NO}_{2}\right)$, ozone $\left(\mathrm{O}_{3}\right)$, and particulate matter with an aerodynamic diameter of $<10 \mu \mathrm{m}\left(\mathrm{PM}_{10}\right)$ for the period February 2002 to July 2016. Background air pollution was measured at the monitoring station of Payerne (part of the Swiss National Air Pollution Monitoring Network). We estimated $\mathrm{NO}_{2}$ exposure using a time-space hybrid model, in order to capture seasonal air pollution variations during the entire study period and spatial variation in different study areas. This model was based on high quality information on land use, population density, traffic, road network, dispersion models, meteorological data, and air quality from the fixed measurement station (i.e. Payerne), trained with $28,849 \mathrm{NO}_{2}$ bi-weekly and monthly passive sampler measurements in the region of Bern. Observations were collected consecutively over more than ten years at 146 locations, for external validation of the model (Proietti et al., 2016). We estimated $\mathrm{PM}_{10}$ and $\mathrm{O}_{3}$ exposure using a simplified spatial-temporal model in which the temporal variation from Payerne was superimposed on the annual dispersion model from Pollumap (METEOTEST, 2018) which provided the spatial contrast in exposures. Thus, in this model, the averaged $\mathrm{PM}_{10}$ per time period (e.g. pregnancy, first year of life), based on daily measurements at the central monitoring site (i.e. Payerne), was corrected for each address using the ratio between the annual dispersion model value at the home address (i.e. Pollumap from METEOTEST, $200 \times 200 \mathrm{~m}$ resolution, 1998-2015 for $\mathrm{PM}_{10}$ and $\mathrm{O}_{3}$ (METEOTEST, 2018)) and the annual mean from Payerne.

From these data we calculated the mean exposure by pollutant for each subject for different exposure windows: pregnancy, annual levels from birth until end of follow-up, as well as short-term exposure, defined as 14 days average before lung function testing at school-age. For families who changed their residential address during the study period, we calculated an average exposure estimate weighted by the time spent at each residence. Addresses were geocoded using a reference file from the Swiss Federal Statistical Office (Neuchâtel).

To assess the degree of air pollution, we compared mean levels of $\mathrm{PM}_{10}, \mathrm{NO}_{2}$, and $\mathrm{O}_{3}$ for all study participants to the annual mean WHO guidelines for each air pollutant (World Health Organization (WHO), 2018; Krzyzanowski, 2008). To assess dose-dependent effects, we parted air pollution exposure into quartiles of the range of each pollutant.

\subsection{Lung function at six years}

Spirometry was performed using the MasterLab setup (Jaeger, Wurzburg, Germany) according to current ERS/ATS guidelines (Beydon et al., 2007). The following lung function parameters were investigated: $\mathrm{FEV}_{1}, \mathrm{FVC}, \mathrm{FEV}_{1} / \mathrm{FVC}$ ratio and mid-expiratory flow at $25-75 \%$ of FVC $\left(\mathrm{MEF}_{25-75 \%}\right)$. A reproducible test was defined as $\mathrm{FVC}$ and $\mathrm{FEV}_{1}$ agreeing within $100 \mathrm{ml}$ or $10 \%$ between the best two blows (Beydon et al., 2007). Spirometry data were expressed as z-scores using the Global Lung Function Initiative (GLI) 2012 prediction equations (Quanjer et al., 2012). Body plethysmography measurements were done to assess the functional residual capacity $\left(\mathrm{FRC}_{\text {pleth }}\right)$, which is the volume of air present in the lungs at the end of passive expiration (Beydon et al., 2007). The mean of three high quality measurements (coefficient of variation $(\mathrm{CV})<25 \%$ between measurements) was calculated.

\subsection{Potential confounders}

At baseline, exposure to potential pre-and postnatal risk factors for lung function deficits was assessed by interviews using standardized 
questionnaires. We assessed environmental tobacco smoke (ETS), an important risk factor for decreased lung function at school-age (Gilliland et al., 2000; He et al., 2011; Pattenden et al., 2006). ETS was defined as passive smoke exposure at work or home during pregnancy, and parental smoking at any time during childhood. Maternal atopic disease was defined as self-reported, doctor-diagnosed asthma, hay fever, or eczema. Parental education was categorized into low (less than four years of apprenticeship), middle (four years of apprenticeship and above) and high (tertiary education). At follow-up, we assessed the asthma diagnosis of the child, defined by wheezing over the past 12 months and doctor diagnosed asthma, or wheezing and use of asthma medication (glucocorticoid or beta mimetic), and short-term air pollution exposure (14 days average before lung function testing).

\subsection{Statistics}

First, we performed univariable linear regression analysis to investigate the association of pulmonary function measures (in z-scores) with mean exposure levels of each pollutant from each exposure window. Second, we adjusted the models for maternal atopy, ETS, asthma of the child and short-term air pollution exposure. Sensitivity analysis was performed using lung function values in ml adjusted for the above-mentioned confounders and additionally adjusted for sex, age and height at lung function. We also performed the analyses not considering the child's asthma status as a confounder. For subgroup analysis, we divided the population into four equally sized groups of 52 participants (quartiles). Quartiles were defined by levels of each air pollutant (for $\mathrm{NO}_{2}, \mathrm{O}_{3}$ and $\mathrm{PM}_{10}$ ) for each time window separately. Changes in lung function parameters are presented as coefficient $(\beta)$ values and $95 \%$ confidence intervals (CIs) per interquartile range (IQR) for each pollutant. Data were analyzed using Stata ${ }^{\circledR}$ (Stata Statistical Software: release 15. STATA Corporation; College Station, TX).

\subsection{Power analysis}

Using Quanto (Gaudermann and Morrison, 2006), we calculated that a sample of 200 subjects would have a power of $>80 \%$, at a significance level of 0.05 to detect changes of $>15 \mathrm{ml}$ in $\mathrm{FEV}_{1}$ per $1 \mu \mathrm{g} / \mathrm{m}^{3}$ increase of $\mathrm{PM}_{10}$.

\section{Results}

Between 2002 and 2010, 304 children were recruited, of which 241 (79\%) eligible study participants completed lung function testing at six years of age. From these, we had complete data on modelled air pollution exposure and lung function measurements at school-age for 232 (96\%), of which spirometry was available for 208 (90\%) and body plethysmography for 212 (91\%) (Fig. S1). Table 1 shows the anthropometric data and potential risk factors. Of the 232 children, 44 (19\%) were exposed to ETS during the study period, 17 (7\%) had asthma at six years, and 89 (38\%) had atopic mothers.

There were differences between children followed-up and those lost to follow-up. Participants followed-up were less often exposed to tobacco smoke during pregnancy ( $5 \%$ vs $11 \%, p=0.042$ ), and born from parents with higher education levels $(p=0.001)$ (Table S1).

Table 2 shows spirometry and body plethysmography data at school-age, completed between the 4th of August 2008 and the 20th of May 2016. For each of the outcome parameters, the summary statistics were: $\mathrm{FEV}_{1}$ (mean z-score; SD) (0.02; 0.87), FVC $(-0.19 ; 0.93)$, and $\mathrm{FEV}_{1} / \mathrm{FVC}(0.45 ; 0.9)$. The $\mathrm{FRC}_{\text {pleth }}$ was (mean ml; SD) $(1105 ; 256)$. The (mean [range]) $\mathrm{CV}$ of body plethysmography was $(6.7 \%[0.7 \%$ to 21.6\%]).

The distribution of air pollution during the study period is given in Table 3.

The distribution of air pollution for each quartile $(n=52)$ is given in Table S2. The WHO guideline limits for $\mathrm{NO}_{2}$ (annual mean $40 \mu \mathrm{g} / \mathrm{m}^{3}$ )
Table 1

Anthropometric data and potential risk factors of the study participants at six years.

\begin{tabular}{ll}
\hline Study participants, n & 232 \\
Age at follow-up, years & $6.1(0.2)$ \\
Length at follow-up, m & $1.17(0.05)$ \\
Weight at follow-up, kg & $22.2(3.3)$ \\
Male sex, n (\%) & $114(49)$ \\
Asthma of the child at follow-up ${ }^{\mathrm{a}}, \mathrm{n}(\%)$ & $17(7)$ \\
Maternal atopy $^{\mathrm{b}}, \mathrm{n}(\%)$ & $89(38)$ \\
Maternal smoking during pregnancy, n (\%) $_{\text {ETS }^{\mathrm{c}}, \mathrm{n}(\%)}$ & $11(5)$ \\
Parental education $^{\mathrm{d}}$ & $44(19)$ \\
Low, n (\%) $_{\text {Middle, n (\%) }}$ & $43(19)$ \\
High, n (\%) & $97(42)$ \\
\end{tabular}

Values are mean (SD) or number (percentage).

a Asthma was defined by wheezing over the past 12 months and doctor diagnosed asthma, or wheezing and use of asthma medication (glucocorticoid or beta mimetic).

b Defined as self-reported, doctor-diagnosed asthma, hay fever or eczema.

c Defined as passive smoke at work or at home during pregnancy, as well as parental smoking any time during follow-up.

d Categorized into low (less than four years of apprenticeship), middle (four years of apprenticeship and above) and high (tertiary education).

Table 2

Lung function data at school-age at six years.

\begin{tabular}{lcc}
\hline Summary of measures & Mean (SD) & Range \\
\hline Spirometry $^{\mathrm{a}}$ & & \\
$\mathrm{FEV}_{1}$ (ml) & $1277(191)$ & $797-1785$ \\
$\mathrm{FEV}_{1}$ (z-scores) & $0.02(0.87)$ & $-2.25-2.41$ \\
FVC (ml) & $1381(235)$ & $816-2251$ \\
FVC (z-scores) & $-0.19(0.93)$ & $-2.70-2.49$ \\
FEV1/FVC & $0.93(0.05)$ & $0.7-1.0$ \\
FEV1/FVC (z-scores) & $0.45(0.93)$ & $-2.46-2.15$ \\
$\mathrm{MEF}_{25-75 \%}$ (ml/s) & $1676(388)$ & $606-2664$ \\
$\mathrm{MEF}_{25-75 \%}$ (z-scores) & $-0.04(0.90)$ & $-2.96-1.94$ \\
Body plethysmography $^{\mathrm{b}}$ & $1105(256)$ & $579-3320$ \\
FRC $_{\text {pleth (ml) }}$ & &
\end{tabular}

Values are means (SD) and range. Lung function measurements are given in $\mathrm{ml}$ and as z-scores according to Quanjer et al. (2012). $\mathrm{FEV}_{1}$, forced expiratory volume in one second; FVC, forced vital capacity; $\mathrm{MEF}_{25-75 \%}$, forced expiratory flow from 25 to $75 \%$ of exhalation. $\mathrm{FRC}_{\text {pleth }}$, function residual capacity measured by body plethysmography.

a Data available for $\mathrm{n}=208$; FVC and $\mathrm{FEV}_{1}$ agreeing within $100 \mathrm{ml}$ between the best two blows.

$\mathrm{b}$ Data available for $\mathrm{n}=212$.

(World Health Organization (WHO), 2018) were not exceeded in our study during any exposure window. However, annual mean $\mathrm{PM}_{10}$ levels of the study participants surpassed the WHO annual guideline limit of $20 \mu \mathrm{g} / \mathrm{m}^{3}$ during pregnancy and the first year of life by $9 \%$ [mean (range) $]\left[21.8 \mu \mathrm{g} / \mathrm{m}^{3} \quad\left(12.5-28.6 \mu \mathrm{g} / \mathrm{m}^{3}\right)\right]$, and $5 \% \quad\left[21.0 \mu \mathrm{g} / \mathrm{m}^{3}\right.$ $\left.\left(10.8-26.8 \mu \mathrm{g} / \mathrm{m}^{3}\right)\right]$, respectively. Air pollution in Switzerland decreased during the study period. Mean $\mathrm{PM}_{10}$ in 2002 was $21.2 \mu \mathrm{g} / \mathrm{m}^{3}$, and $12.8 \mu \mathrm{g} / \mathrm{m}^{3}$ in 2016. Mean $\mathrm{NO}_{2}$ in 2002 was $14.7 \mu \mathrm{g} / \mathrm{m}^{3}$, and $11.3 \mu \mathrm{g} / \mathrm{m}^{3}$ in 2016 . Annual $\mathrm{O}_{3}$ levels were not comparable to the WHO guideline limits as these were only defined as $8 \mathrm{~h}$ means $(8 \mathrm{~h}$ mean $100 \mu \mathrm{g} / \mathrm{m}^{3}$ ), rather than annual means as performed in this study. The temporal decrease of $\mathrm{NO}_{2}$ for each quartile is shown in Fig. 1.

The highest exposed group was exposed to $\mathrm{NO}_{2}$ levels of [mean (range)] [26.1 $\mu \mathrm{g} / \mathrm{m}^{3}\left(22.0 \mu \mathrm{g} / \mathrm{m}^{3}\right.$ to $\left.37.2 \mu \mathrm{g} / \mathrm{m}^{3}\right)$ ] during pregnancy, and during sixth year of life to $\mathrm{NO}_{2}$ levels of $\left[18.3 \mu \mathrm{g} / \mathrm{m}^{3}\left(14.4 \mu \mathrm{g} / \mathrm{m}^{3}\right.\right.$ to $\left.\left.26.6 \mu \mathrm{g} / \mathrm{m}^{3}\right)\right]$. The lowest exposed group was exposed to $\mathrm{NO}_{2}$ levels of [12.3 $\mu \mathrm{g} / \mathrm{m}^{3}$ (10.4 to $\left.14.1 \mu \mathrm{g} / \mathrm{m}^{3}\right)$ ] during pregnancy, and during sixth year of life to $\mathrm{NO}_{2}$ levels of $\left[8.4 \mu \mathrm{g} / \mathrm{m}^{3}\left(7.0 \mu \mathrm{g} / \mathrm{m}^{3}\right.\right.$ to $\left.\left.9.6 \mu \mathrm{g} / \mathrm{m}^{3}\right)\right]$, respectively (Table S2). 
Table 3

Distribution of estimated residential outdoor air pollutants.

\begin{tabular}{|c|c|c|c|c|}
\hline & Mean & (SD) & Range & IQR \\
\hline \multicolumn{5}{|l|}{$\mathrm{NO}_{2} \mu \mathrm{g} \cdot \mathrm{m}^{-3}$} \\
\hline Entire pregnancy & 18.5 & $(5.5)$ & $10.4-37.2$ & 8.0 \\
\hline 1st year of life & 17.6 & $(5.1)$ & $9.4-34.4$ & 7.2 \\
\hline 6th year of life & 12.8 & $(4.0)$ & $7.0-26.6$ & 4.9 \\
\hline From birth until follow-up & 15.0 & $(4.3)$ & $8.5-30.2$ & 5.3 \\
\hline Exposure at follow-up ${ }^{a}$ & 11.8 & $(4.7)$ & $4.9-35.9$ & 5.9 \\
\hline \multicolumn{5}{|l|}{$\mathrm{O}_{3} \mu \mathrm{g} \cdot \mathrm{m}^{-3}$} \\
\hline Entire pregnancy & 87.3 & $(10.5)$ & $68.6-114.9$ & 14.5 \\
\hline 1st year of life & 87.0 & $(5.6)$ & $76.1-99.4$ & 8.7 \\
\hline 6th year of life & 83.8 & $(4.7)$ & $65.0-96.1$ & 6.0 \\
\hline From birth until follow-up & 85.0 & $(4.1)$ & $74.4-95.3$ & 6.0 \\
\hline Exposure at follow-up ${ }^{a}$ & 88.3 & (30.3) & $10.1-163.4$ & 50.6 \\
\hline \multicolumn{5}{|l|}{$\mathrm{PM}_{10} \mu \mathrm{g} \cdot \mathrm{m}^{-3}$} \\
\hline Entire pregnancy & 21.8 & (3.3) & $12.5-28.6$ & 4.4 \\
\hline 1st year of life & 21.0 & $(2.8)$ & $10.8-26.8$ & 3.1 \\
\hline 6th year of life & 17.9 & $(2.6)$ & $9.8-25.8$ & 3.1 \\
\hline From birth until follow-up & 19.4 & $(2.4)$ & $10.6-23.6$ & 3.2 \\
\hline Exposure at follow-up ${ }^{a}$ & 17.5 & (7.9) & $5.4-52.5$ & 7.9 \\
\hline
\end{tabular}

Values are means (SD), range and IQR.

a 14 days average before lung function testing during follow-up at six years; data available for $\mathrm{n}=232$.

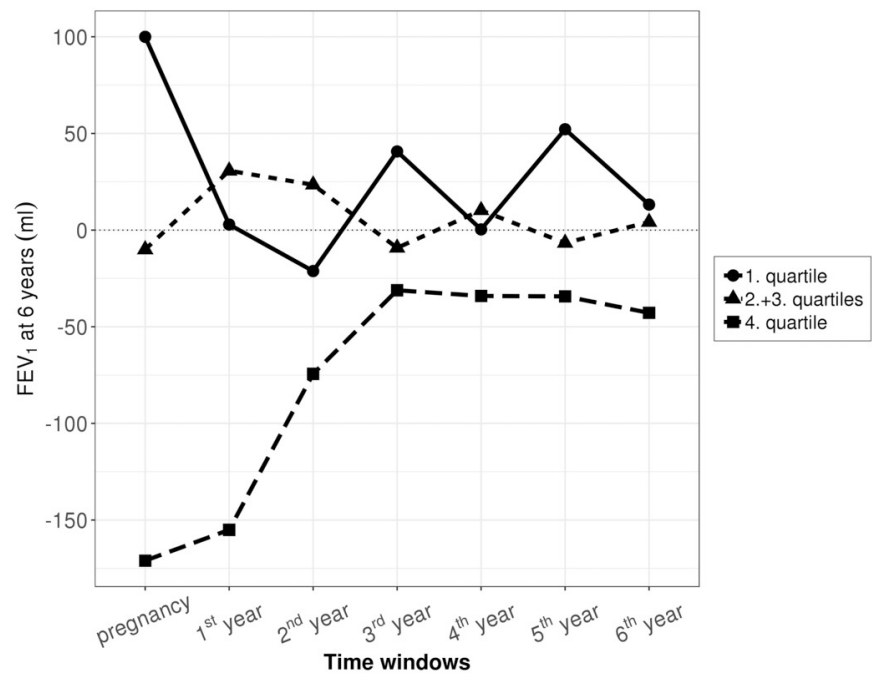

Fig. 1. Temporal development of mean $\mathrm{NO}_{2}$ levels $\left(\mu \mathrm{g} / \mathrm{m}^{3}\right)$ for each quartile. Temporal development over all investigated time windows (pregnancy, 1st year, 2nd year, 3rd year, 4th year, 5th year, 6th year). The population was divided into quartiles by individual $\mathrm{NO}_{2}$ levels $\left(\mu \mathrm{g} / \mathrm{m}^{3}\right)$; data available for $\mathrm{n}=208$, per quartile $\mathrm{n}=52$.

\subsection{Association of different air pollution exposure windows with lung function at six years}

\subsubsection{Spirometry}

Air pollution exposure during pregnancy was associated with reduced $\mathrm{FEV}_{1}$ at six years (Table S3). In the adjusted regression model, per IQR increase in $\mathrm{NO}_{2}$ during pregnancy $\left(8.0 \mu \mathrm{g} / \mathrm{m}^{3}\right)$ and from birth until follow-up $\left(5.2 \mu \mathrm{g} / \mathrm{m}^{3}\right), \mathrm{FEV}_{1}$ decreased by [z-score change $(95 \%$ confidence interval)] $[-0.16(-0.35$ to 0.04$)]$ and significantly by [ $-0.24(-0.45$ to -0.02$)]$, respectively. Per IQR increase in $\mathrm{O}_{3}$ during pregnancy $\left(14.6 \mu \mathrm{g} / \mathrm{m}^{3}\right)$ and from birth until follow-up $\left(5.9 \mu \mathrm{g} / \mathrm{m}^{3}\right)$, $\mathrm{FEV}_{1}$ decreased by $[-0.11(-0.29$ to 0.06$)$, and significantly by $[-0.24(-0.45$ to -0.02$)]$, respectively. Per IQR increase in $\mathrm{PM}_{10}$ during pregnancy $\left(4.4 \mu \mathrm{g} / \mathrm{m}^{3}\right)$ and from birth until follow-up $(3.3 \mu \mathrm{g}$ / $\left.\mathrm{m}^{3}\right), \mathrm{FEV}_{1}$ decreased by $[-0.14(-0.30$ to 0.14$)]$ and by $[-0.09$ $(-0.26$ to 0.08$)$ ], respectively. Results reported per ml change in $\mathrm{FEV}_{1}$ are given in Table 4. Similar associations were found for the other time windows (second, third, fourth and fifth year of life) and $\mathrm{FEV}_{1}$ at six years (data not shown).

\subsubsection{Dose and age dependent effects on spirometry}

Adverse effects of air pollution exposure on lung function depended upon the exposure level. Regression analysis of the quartiles showed significant negative associations of $\mathrm{NO}_{2}$ levels with $\mathrm{FEV}_{1}$ in the highest exposed group. In this subgroup, per IQR increase in $\mathrm{NO}_{2}$ during pregnancy $\left(8.0 \mu \mathrm{g} / \mathrm{m}^{3}\right)$, during the first year of life $\left(7.2 \mu \mathrm{g} / \mathrm{m}^{3}\right)$, during the second year of life $\left(5.7 \mu \mathrm{g} / \mathrm{m}^{3}\right)$ and from birth until follow-up $\left(5.2 \mu \mathrm{g} / \mathrm{m}^{3}\right), \mathrm{FEV}_{1}$ decreased highly significant $(p=0.001)$ by $[-1.07$ $(-1.67$ to -0.47$)]$, by $[-1.02(-1.66$ to -0.39$)]$, by $[-0.51(-0.86$ to -0.17$)]$ and by $[-0.80(-1.33$ to -0.27$)]$ respectively.

There was no significant association of $\mathrm{NO}_{2}$ and $\mathrm{FEV}_{1}$ at six years in the subgroup with the lowest exposure levels. In this subgroup $(\mathrm{n}=52)$, per IQR increase in $\mathrm{NO}_{2}$ during pregnancy $\left(8.0 \mu \mathrm{g} / \mathrm{m}^{3}\right)$, during the first year of life $\left(7.2 \mu \mathrm{g} / \mathrm{m}^{3}\right)$, during the second year of life $\left(5.7 \mu \mathrm{g} / \mathrm{m}^{3}\right)$ and from birth until follow-up $\left(5.2 \mu \mathrm{g} / \mathrm{m}^{3}\right), \mathrm{FEV}_{1}$ decreased non-significantly by $[-0.21(-2.05$ to 1.63$)],[-0.15(-1.97$ to $1.67)],[-0.88(-2.37$ to 0.60$)]$ and $[-0.36(-1.97$ to 1.24$)]$, respectively (Table S4). Within the other quartiles, also non-significant effects of $\mathrm{NO}_{2}$ levels on $\mathrm{FEV}_{1}$ were observed (Fig. 2, Table S4). $\mathrm{O}_{3}$ and $\mathrm{PM}_{10}$ exposure during investigated time windows were associated with a non-significant $\mathrm{FEV}_{1}$ decrease for all investigated exposure windows (Tables S5, S6).

\subsubsection{Spirometry sensitivity analysis}

In a sensitivity analysis, we did not adjust for the child's asthma status at six years, which resulted in similar but weaker associations between air pollution and $\mathrm{FEV}_{1}$ at six years. For example, in the entire study sample (and not investigating exposure groups), in the adjusted regression models not adjusted for asthma, per IQR increase in $\mathrm{NO}_{2}$ during pregnancy and from birth until follow-up, $\mathrm{FEV}_{1}$ decreased by [zscore change ( $95 \%$ confidence interval)] $[-0.14(-0.34$ to 0.07$)]$ and by $[-0.21(-0.44$ to -0.01$)]$, respectively (Table S7).

Adverse effects of $\mathrm{NO}_{2}$ exposure in the highest exposure group and spirometry parameters at six years were also very similar when we did not consider the child's asthma status as a confounder. In this subgroup, per IQR increase in $\mathrm{NO}_{2}$ during pregnancy, the first year of life, the second year of life and from birth until follow-up, $\mathrm{FEV}_{1}$ decreased by [ $-1.07(-1.66$ to -0.46$)]$, by $[-1.01(-1.64$ to -0.38$)]$, by $[-0.51$ $(-0.85$ to -0.17$)]$ and by $[-0.79(-1.31$ to -0.27$)]$, respectively (Table S8).

\subsubsection{Body plethysmography}

The association of exposure to air pollution during pregnancy and childhood with lung volume assessed at six years is given in Table S9 in the online supplement. Air pollution exposure during pregnancy and childhood resulted in a non-significant decrease in lung volume, as assessed by $\mathrm{FRC}_{\text {pleth }}$.

\section{Discussion}

\subsection{Main findings}

To our knowledge, this is the first study to examine moderate air pollution exposure before and after birth and the association with airway obstruction and lung volume at school-age. We defined several exposure windows (pregnancy, first year of life, sixth year of life, and birth until follow-up at six years) to examine the dose-dependent impact of air pollution from different exposure time points on lung function at school-age.

When analyzing the entire study population, $\mathrm{NO}_{2}$ exposure during pregnancy and the first year of life was weakly associated with a decrease in $\mathrm{FEV}_{1}$ at school-age. In order to investigate dose-dependent exposure groups, $\mathrm{NO}_{2}$ exposure was categorized into quartiles. Children 
Table 4

Association of air pollution during different exposure windows with spirometry (in ml) at six years.

\begin{tabular}{|c|c|c|c|c|c|c|c|}
\hline \multirow[b]{3}{*}{ Exposure } & & \multicolumn{2}{|c|}{ Univariable association } & \multicolumn{4}{|c|}{ Multivariable association $^{\mathrm{a}}$} \\
\hline & & \multicolumn{6}{|c|}{$\mathrm{FEV}_{1}(\mathrm{ml})$} \\
\hline & & Coef & $95 \%$ CI & $p$-Value & Coef & $95 \% \mathrm{CI}$ & $p$-Value \\
\hline \multirow[t]{5}{*}{$\mathrm{NO}_{2}$} & Pregnancy & 12.0 & $(-25.6,49.7)$ & 0.530 & -25.2 & $(-57.4,7.1)$ & 0.125 \\
\hline & 1 st year of life & -9.1 & $(-28.8,47.1)$ & 0.636 & -25.6 & $(-59.6,8.4)$ & 0.140 \\
\hline & 6th year of life & -1.0 & $(-32.4,30.4)$ & 0.949 & -40.5 & $(-76.4,-4.7)$ & 0.027 \\
\hline & Birth until follow-up & 1.4 & $(-30.8,33.6)$ & 0.933 & -37.7 & $(-72.3,-3.1)$ & 0.033 \\
\hline & Short-term exposure & 18.7 & $(-11.8,49.2)$ & 0.229 & 6.7 & $(-16.2,29.6)$ & 0.565 \\
\hline \multirow[t]{5}{*}{$\mathrm{O}_{3}$} & Pregnancy & -25.1 & $(-60.8,10.7)$ & 0.168 & -20.4 & $(-48.5,7.7)$ & 0.154 \\
\hline & 1 st year of life & -0.8 & $(-39.9,38.3)$ & 0.968 & -16.5 & $(-45.0,11.9)$ & 0.253 \\
\hline & 6th year of life & 27.2 & $(-6.6,61.0)$ & 0.114 & 4.6 & $(-20.7,29.9)$ & 0.719 \\
\hline & Birth until follow-up & 4.3 & $(-33.7,42.3)$ & 0.823 & -21.2 & $(-49.1,6.8)$ & 0.138 \\
\hline & Short-term exposure & -35.9 & $(-79.4,7.7)$ & 0.106 & -40.7 & $(-72.9,-8.5)$ & 0.013 \\
\hline \multirow{5}{*}{$\mathrm{PM}_{10}$} & Pregnancy & -4.1 & $(-39.0,30.8)$ & 0.817 & -23.5 & $(-49.6,2.6)$ & 0.078 \\
\hline & 1st year of life & 8.7 & $(-20.7,38.2)$ & 0.559 & 0.16 & $(-22.4,22.7)$ & 0.989 \\
\hline & 6th year of life & 0.6 & $(-30.9,32.0)$ & 0.973 & -13.6 & $(-38.4,11.1)$ & 0.279 \\
\hline & Birth until follow-up & 2.1 & $(-33.3,37.6)$ & 0.906 & -13.5 & $(-41.0,14.0)$ & 0.333 \\
\hline & Short-term exposure & 27.1 & $(1.3,52.8)$ & 0.039 & 5.8 & $(-13.9,25.4)$ & 0.565 \\
\hline
\end{tabular}

Univariable and multivariable linear regression models for the association per IQR increase of $\mathrm{NO}_{2}, \mathrm{O}_{3}$, and $\mathrm{PM}_{10}$ with lung functional measurements in milliliters at six years.

a Multivariable model adjusted for sex, child's age, height, child's diagnosis of asthma, maternal atopy, environmental tobacco exposure and short-term exposure to

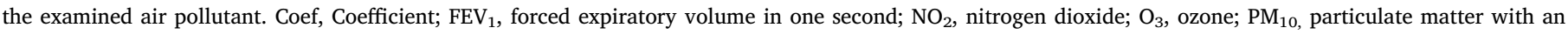
aerodynamic diameter of $<10 \mu \mathrm{m}$; data available for $\mathrm{n}=208$.

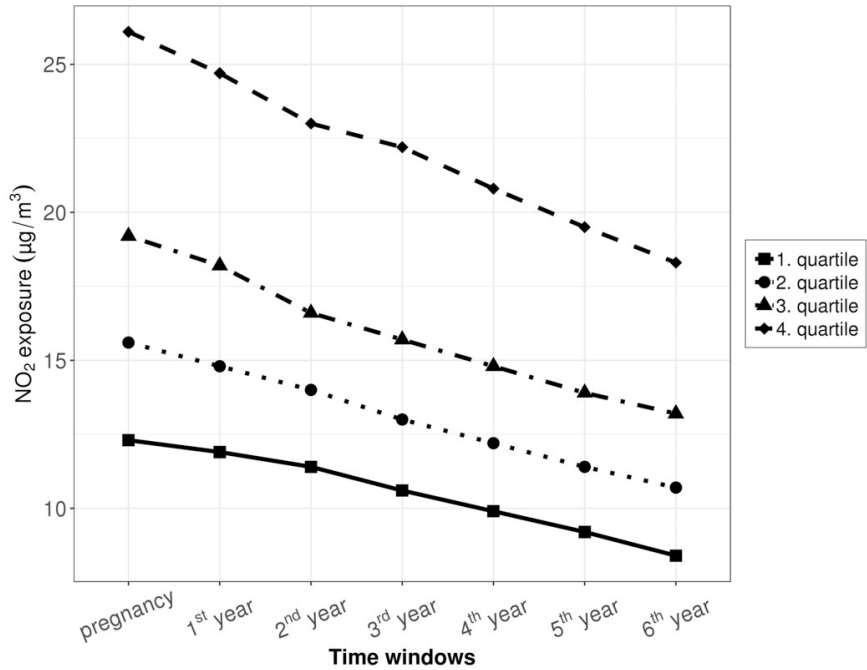

Fig. 2. Effect of $\mathrm{NO}_{2}$ levels $\left(\mu \mathrm{g} / \mathrm{m}^{3}\right)$ on $\mathrm{FEV}_{1}(\mathrm{ml})$ at six years. The population was divided into quartiles by individual $\mathrm{NO}_{2}$ levels (per quartile $\mathrm{n}=52$ ). This resulted in low exposed (1st quartile), mid-exposed (2nd and 3rd quartile), and highest exposed (4th quartile) subgroups. $\mathrm{NO}_{2}\left(\mu \mathrm{g} / \mathrm{m}^{3}\right)$ during different time windows (pregnancy, 1st year, 2nd year, 3rd year, 4th year, 5th year, 6th year) and its effects on $\mathrm{FEV}_{1}(\mathrm{ml})$ at six years was calculated for 1st quartile, 2nd and 3rd quartile combined, and 4th quartile. Data available for $n=208$.

in the highest exposure group (mean annual $\mathrm{NO}_{2}$ exposure above $20 \mu \mathrm{g} /$ $\mathrm{m}^{3}$ ) had a significant decrease in $\mathrm{FEV}_{1}$ at school-age. This effect was observed for exposure during pregnancy and early childhood, indicating that early lung development is especially sensitive to air pollution exposure. Children exposed to lower $\mathrm{NO}_{2}$ levels (mean annual $\mathrm{NO}_{2}$ exposure below $20 \mu \mathrm{g} / \mathrm{m}^{3}$ ) had no decrease in lung function at school-age. Together, these findings support the hypothesis of dosedependent effects of air pollutants on lung function, especially observed in young infants exposed to high levels of $\mathrm{NO}_{2}$.

\subsection{Comparison with literature}

There are several studies demonstrating the effects of higher air pollution exposure and reduced lung function during childhood and adolescence, underlying the clinical relevance of air pollution on lung growth (Jedrychowski et al., 2010; Morales et al., 2015; Deng et al., 2016) and later respiratory morbidity in the elderly (Bush, 2016; Postma et al., 2015; Stern et al., 2007; Tai et al., 2014). In regard to studies with lower air pollution exposure levels, a previous populationbased cohort in Sweden calculated air pollution exposure from birth until follow-up at eight years and measured lung function at follow-up in almost 2000 children (Schultz et al., 2012). In that study, different exposure windows were calculated and mean levels of $\mathrm{PM}_{10}$ were lower than in our study. Per $7 \mu \mathrm{g} / \mathrm{m}^{3}$ increase in $\mathrm{PM}_{10}$, which was equal to the difference between the 5th and 95th percentile, the authors reported a decrease of $-59.3 \mathrm{ml}$ in $\mathrm{FEV}_{1}$ in the whole study population, which was more pronounced in boys and susceptible subgroups (e.g. children sensitized to common allergens). In our population, $\mathrm{PM}_{10}$ exposure during the first year of life was not significantly associated with reduced $\mathrm{FEV}_{1}$. However, an increase of $7.7 \mu \mathrm{g} / \mathrm{m}^{3} \mathrm{PM}_{10}$, assessed from birth until six years of age, which was equal to the difference between the 5 th and 95th percentile, resulted in a $-24.0 \mathrm{ml}$ decrease in $\mathrm{FEV}_{1}$.

These differences may be explained by several mechanisms. Our population of six-year-olds has lower mean $\mathrm{FEV}_{1}$ values compared to the eight-year-olds in the study by Schultz et al. (Schultz et al., 2012) $(1277 \mathrm{ml} v \mathrm{vs} 1780 \mathrm{ml})$, and hence, adverse effects of air pollution may result in a lower absolute reduction in $\mathrm{FEV}_{1}$ due to lower lung volumes. When expressing the reduction in $\mathrm{FEV}_{1}$ in percent change, per $7 \mu \mathrm{g} /$ $\mathrm{m}^{3} \mathrm{PM}_{10}$ increase, Schultz et al. measured a $\mathrm{FEV}_{1}$ decrease of $3.3 \%$, while we observed a $\mathrm{FEV}_{1}$ decrease of $1.9 \%$. Reasons underlying these differences may be related to different statistical models and adjustments, a different assessment of air pollution exposure, as well as exposure to different risk factors (e.g. environmental and genetic). Results from a large cohort study in the area of Paris support our findings. Bougas and Ranciere reported associations of pre-and postnatal exposure to $\mathrm{NO}_{\mathrm{x}}\left(\mathrm{NO}\right.$ and $\left.\mathrm{NO}_{2}\right)$ and lung function parameters at 8-9 years of age (Bougas and Ranciere, 2018), with more pronounced effects observed in vulnerable subgroups (e.g. children with early lower respiratory tract infections or allergic sensitization). Of note, exposure levels of $\mathrm{NO}_{2}$ measured from birth until lung function in that study were approximately four times higher (median $\mathrm{NO}_{2} 65.4 \mu \mathrm{g} / \mathrm{m}^{3}$ ) than exposure levels in our study (median $\mathrm{NO}_{2} 14.2 \mu \mathrm{g} / \mathrm{m}^{3}$ ).

A large cohort study in the US investigated the association of air 
quality regulations in the 1990s, and lung function in 600 eight year old children. The authors found no significant associations between air pollution exposure and lung function, except for $\mathrm{PM}_{2.5}$ exposure one year before lung functional testing, and reduced $\mathrm{FEV}_{1}$ values (Rice et al., 2016). This weak association supports our findings, where we adjusted rigorously for potential confounders (e.g. short-term air pollution exposure, asthma status of the child), and found only weak associations within the overall population. As the observed decrease in $\mathrm{FEV}_{1}$ in our study reached significance level mainly for children in the highest $\mathrm{NO}_{2}$ exposure group, we conclude that current air pollution exposure in Switzerland is associated with only small reductions in lung function at school-age. However, the small reductions in lung function as reported in this and previous studies (Jedrychowski et al., 2010; Morales et al., 2015; Schultz et al., 2012) should encourage further reduction in ambient air pollution levels to protect susceptible children during vulnerable time windows of lung development.

Previous studies measured pollutants at one to three time points, and found associations with reduced lung function (Jedrychowski et al., 2010; Morales et al., 2015; Schultz et al., 2012; Gehring et al., 2013). Such an approach may have its limitations, however, since air pollution exposure reflects only a snap shot, and mean individual exposure levels during longer time periods may differ. This may have led to an overestimation of air pollution effects, especially when air pollution decreases over time and the pollutants were measured at an early time point and these estimates were used for the whole study period (Schultz et al., 2012; Gauderman et al., 2015). Furthermore, in order to not report spurious associations, studies should attempt to approximate exposure levels as precisely as possible, taking into account spatial and temporal variation, as factors such as proximity to major roads and short-term air pollutant exposure, are known to impact upon individual exposure levels (Proietti et al., 2016; Linares et al., 2010).

We observed a relevant decline in air pollutant levels over the 14year study period (Fig. 1).

$\mathrm{NO}_{2}$ within our overall population decreased nearly $30 \%$ (from $20.6 \mu \mathrm{g} / \mathrm{m}^{3}$ to $14.4 \mu \mathrm{g} / \mathrm{m}^{3}$ ) between 2002 and 2010 . While in $200230 \%$ of all infants were exposed to $\mathrm{NO}_{2}$ levels $>20 \mu \mathrm{g} / \mathrm{m}^{3}$, in 2010 only $16 \%$ remained exposed to these levels. This finding is encouraging, since recent attempts to reduce air pollutant exposure, at least in Switzerland, were effective (Bundesamt für Umwelt (BAFU) Schweiz, 2018). Gauderman et al. investigated the effect of a decrease in air pollution levels on lung development in eleven-year-old children up to 15-year-old adolescents (Gauderman et al., 2015), but not at earlier ages. For an increase of $2 \mu \mathrm{g} / \mathrm{m}^{3}$ in $\mathrm{PM}_{2.5}$, they observed a decrease of $-21.8 \mathrm{ml}$ in FVC. Nevertheless, the study by Gauderman et al. did not track longitudinal lung function on an individual level, or at a young age (Gauderman et al., 2015). The study is, however, important as it was the first to report improved lung function due to reduced air pollution in a large cohort, and underlines the necessity to measure pollutant levels continuously in prospective studies. Assessing more precise exposure estimates could help to better evaluate the effects of improved air quality on children's health, especially when air pollution decreases over time.

\subsection{Clinical and physiological relevance}

Air pollution has detrimental effects on lung development, especially in areas with higher exposure levels (Morales et al., 2015; Deng et al., 2016; Hsu et al., 2015; Tsui et al., 2018). Depending on the assessment of the pollutant, time period of interest, and study areas, the reported adverse effects differ (Schultz et al., 2012; Rice et al., 2016; Gauderman et al., 2015; Hoek et al., 2012). Although the absolute effect of some pollutants may seem small, a decline in lung function may be most significant for those starting with impaired lung function early in life (e.g. preterm infants) or susceptible subjects (e.g. cystic fibrosis patients) (Goeminne et al., 2013; Hoo et al., 2002; McGeachie et al., 2016).
Preschool $\mathrm{NO}_{2}$ exposure was associated with impaired lung function at six years of age, whether or not the multivariable model adjusted for the child's asthma status. One reason for this could be that air pollution has a direct impact upon lung functional growth, and not only as the result of asthma-related airway obstruction.

We observed an association between higher air pollution levels and reduced $\mathrm{FEV}_{1}$, but not with $\mathrm{FRC}_{\text {pleth }}$ at six years of age. This finding may be due to different breathing manoeuvres used during lung function testing. For spirometry (to assess $\mathrm{FEV}_{1}$ ) the child breathes at the mechanical limits of the respiratory system (flow limitation). This typically results in lower variability of forced flow lung function parameters. During body plethysmography, the child breathes closer to FRC. At FRC, the respiratory system exhibits more adaptive variability of the airway resistance and thus small deleterious effects of air pollutants might not be detectable. These physiological differences may explain why the small impact of air pollution on lung function may only become measurable when assessed at the extreme, which is during forced breathing manoeuvres, but not during regular FRC breathing. Nevertheless, data are consistent with the impact of low-level air pollution on airway obstruction (Schultz et al., 2012). Further, air pollution is just one parameter resulting in reduced lung function, and other factors, such as toxins (e.g. ETS), as well as physiological decline over time, should be considered. Hence, even though low-level air pollution may have only small adverse effects, children exposed to moderate-tohigh air pollution levels during susceptible time windows showed a significant decrease in lung function (Bougas and Ranciere, 2018; Morales et al., 2015; Deng et al., 2016; Roy et al., 2012), which might lead to later respiratory morbidity in the elderly (Bush, 2016; Postma et al., 2015; Stern et al., 2007; Tai et al., 2014). Therefore, further attempts should be made to reduce air pollution levels in order to minimize detrimental effects.

\subsection{Strengths and limitations}

One strength of our study was the assessment of air pollution during pregnancy and after birth, enabling us to study different exposure windows. To our knowledge, this is the first study to assess low-tomoderate levels of pre- and postnatal air pollution and association with airway obstruction and lung volume. We estimated $\mathrm{NO}_{2}$ continuously using models based on bi-weekly measurements over the whole study period and validated it with independent data (Proietti et al., 2016). Lung function was performed at one center by trained staff reducing potential inter-center differences. Especially in young children, precision of measurements largely depends on the child's ability to perform the breathing manoeuvres, and only high-quality measurements were included.

Children lost to follow-up had significantly less educated parents and were more often exposed to ETS compared to those followed-up. A lower rate of ETS exposure in those children investigated may have led to a selection of children with potentially better lung function at schoolage.

Due to a limited sample size, we could only perform subgroup analyses by dividing participants into quartiles depending on their exposure level, but could not perform additional subgroup analyses. Therefore, we cannot conclude on the impact of air pollution in susceptible subgroups (e.g. children with asthma), as reported by others (Schultz et al., 2012; Rice et al., 2016). Our analyses were adjusted for known confounders impacting upon the association between air pollution and reduced lung function, but the possibility of residual confounding remains.

When looking at the whole study population, we observed small effects of higher $\mathrm{NO}_{2}$ exposure during the entire study period (pregnancy until six years) with reduced $\mathrm{FEV}_{1}$ values at school-age. This effect became even more obvious in the highest exposed group, in which $\mathrm{NO}_{2}$ exposure $>20 \mu \mathrm{g} / \mathrm{m}^{3}$ during pregnancy and the 1 st and 2nd years of life was associated with severely reduced lung function at 
school age. This indicates that $\mathrm{NO}_{2}$ exposure $>20 \mu \mathrm{g} / \mathrm{m}^{3}$ may be a critical exposure level. We are unable to conclude on critical exposure levels of $\mathrm{NO}_{2}$ during later childhood (5th and 6th years of life), since exposure levels at later time points were on average lower $(<20 \mu \mathrm{g}$ / $\mathrm{m}^{3}$ ) due the natural decline of air pollution over the course of the study period.

\subsection{Conclusion and implications}

In this study, we found associations between moderate air pollution exposure assessed before birth and during early childhood and lung function at school-age on a population level in healthy children. Stronger associations between air pollution and reduced $\mathrm{FEV}_{1}$ values were observed in a subgroup exposed to the highest pollution levels above $20 \mu \mathrm{g} / \mathrm{m}^{3} \mathrm{NO}_{2}$. It is remarkable that in infants these dose-dependent effects are unexpectedly observed even at $\mathrm{NO}_{2}$ values below the WHO guideline limits of $40 \mu \mathrm{g} / \mathrm{m}^{3}$ (World Health Organization (WHO), 2018). Thus, functional growth impairment may already be present, if infants are exposed to low-level air pollution during pregnancy and the first two years of life, time windows of rapid lung growth and potentially vulnerable lung development. In order to protect the vulnerable infant population and to develop health policies, further studies are needed to particularly investigate the relative impact of exposure during young age and low-level air pollution. Not only age, but also other preexisting risk factors (e.g. male sex, allergic sensitization (Schultz et al., 2012)), may affect vulnerability to air pollution in small infants, requiring large multicenter birth cohort air pollution studies with a wide range of accurately measured air pollution exposures. There is sufficient evidence in the literature (Bush, 2016; Postma et al., 2015; Stern et al., 2007; Tai et al., 2014), that impaired early life lung functional growth is associated with later respiratory morbidity in the elderly. Thus, impairment of lung functional growth at even low concentrations will affect a large proportion of the normal healthy population and will potentially have a significant impact on public health in the future.

\section{Acknowledgments}

\section{Funding}

This work was supported by the Swiss National Science Foundation grant 320030_163311 and a research fellowship of the UKBB issued to J. Usemann. The authors thank all the study participants for participating in the study, the entire BILD cohort team (University of Basel Children's Hospital, Switzerland; Division of Respiratory Medicine, Department of Pediatrics, Inselspital, Bern University Hospital, University of Bern, Switzerland), Karine Hugentobler (University of Basel Children's Hospital) for her critical reading of the manuscript, METEOTEST for providing Pollumap and its GIS information.

\section{Competing interest}

The authors have no conflicts of interest to declare.

\section{Contributions}

UF conceived the study. Measurements were recorded by JU, OF, IK, EP, AS, and PL. EP, DV and MR developed the $\mathrm{NO}_{2}$ air pollution model. DV derived the $\mathrm{PM}_{10}$ and $\mathrm{O}_{3}$ exposure estimates. Statistical analyses were performed by FD, JU, IK and OG. FD and JU drafted the manuscript; all authors have seen and approved the final manuscript.

\section{Patient consent}

Obtained.

\section{Ethics approval}

The Ethics Committee of the Region of Bern approved the study.

\section{Appendix A. Supplementary data}

Supplementary data to this article can be found online at https:// doi.org/10.1016/j.envint.2018.12.019.

\section{References}

Beydon, N., et al., 2007. An official American Thoracic Society/European Respiratory Society statement: pulmonary function testing in preschool children. Am. J. Respir. Crit. Care Med. 175 (12), 1304-1345.

Bougas, N., Ranciere, F., 2018. Traffic-related air pollution, lung function, and host vulnerability. New insights from the PARIS birth cohort. 15 (5), 599-607.

Bundesamt für Umwelt (BAFU) Schweiz, 2018. Topic air. [Website] 30.03.2018]; Available from. https://www.bafu.admin.ch/bafu/en/home/topics/air/in-brief. html.

Bush, A., 2016. Lung development and aging. Ann. Am. Thorac. Soc. 13 (Supplement_5), S438-s446.

Deng, Q., et al., 2016. Exposure to outdoor air pollution during trimesters of pregnancy and childhood asthma, allergic rhinitis, and eczema. Environ. Res. 150, 119-127.

Fuchs, O., et al., 2012. Cohort profile: the Bern infant lung development cohort. Int. J. Epidemiol. 41 (2), 366-376.

Gauderman, W.J., et al., 2015. Association of improved air quality with lung development in children. N. Engl. J. Med. 372 (10), 905-913.

Gaudermann, W.J., Morrison, F.M., 2006. Quanto 1.1: a computer program for power and sample size calculations for genetic-epidemiology studies. Mai 2015, Available from: http://biostats.usc.edu/Quanto.html (n.d.).

Gehring, U., et al., 2013. Air pollution exposure and lung function in children: the ESCAPE project. Environ. Health Perspect. 121 (11-12), 1357-1364.

Gilliland, F.D., et al., 2000. Maternal smoking during pregnancy, environmental tobacco smoke exposure and childhood lung function. Thorax 55 (4), 271-276.

Goeminne, P.C., et al., 2013. Impact of air pollution on cystic fibrosis pulmonary exacerbations: a case-crossover analysis. Chest 143 (4), 946-954.

He, Q.Q., et al., 2011. Environmental tobacco smoke exposure and Chinese schoolchildren's respiratory health: a prospective cohort study. Am. J. Prev. Med. 41 (5), 487-493.

Hoek, G., et al., 2012. PM10, and children's respiratory symptoms and lung function in the PATY study. Eur. Respir. J. 40 (3), 538-547.

Hoo, A.F., et al., 2002. Development of airway function in infancy after preterm delivery. J. Pediatr. 141 (5), 652-658.

Hsu, H.H., et al., 2015. Prenatal particulate air pollution and asthma onset in urban children. Identifying sensitive windows and sex differences. Am. J. Respir. Crit. Care Med. 192 (9), 1052-1059.

Jedrychowski, W.A., et al., 2010. Effect of prenatal exposure to fine particulate matter on ventilatory lung function of preschool children of non-smoking mothers. Paediatr. Perinat. Epidemiol. 24 (5), 492-501.

Jedrychowski, W.A., et al., 2015. Long term effects of prenatal and postnatal airborne PAH exposures on ventilatory lung function of non-asthmatic preadolescent children. Prospective birth cohort study in Krakow. Sci. Total Environ. 502, 502-509.

Korten, I., Ramsey, K., Latzin, P., 2017. Air pollution during pregnancy and lung development in the child. Paediatr. Respir. Rev. 21, 38-46.

Krzyzanowski, M., 2008. WHO air quality guidelines for Europe. J. Toxic. Environ. Health A 71 (1), 47-50.

Latzin, P., et al., 2009. Air pollution during pregnancy and lung function in newborns: a birth cohort study. Eur. Respir. J. 33 (3), 594-603.

Linares, B., et al., 2010. Impact of air pollution on pulmonary function and respiratory symptoms in children. Longitudinal repeated-measures study. BMC Pulm. Med. $10,62$.

McGeachie, M.J., et al., 2016. Patterns of growth and decline in lung function in persistent childhood asthma. N. Engl. J. Med. 374 (19), 1842-1852.

METEOTEST, 2018. Immissionskarten. 30.03.2018, Available from. https://meteotest. ch/produkt/immissionskarten.

Morales, E., et al., 2015. Intrauterine and early postnatal exposure to outdoor air pollution and lung function at preschool age. Thorax 70 (1), 64-73.

Mortimer, K., et al., 2008. Air pollution and pulmonary function in asthmatic children: effects of prenatal and lifetime exposures. Epidemiology 19 (4), 550-557 (discussion 561-2).

Pattenden, S., et al., 2006. Parental smoking and children's respiratory health: independent effects of prenatal and postnatal exposure. Tob. Control. 15 (4), 294-301.

Postma, D.S., Bush, A., van den Berge, M., 2015. Risk factors and early origins of chronic obstructive pulmonary disease. Lancet 385 (9971), 899-909.

Proietti, E., et al., 2016. Air pollution modelling for birth cohorts: a time-space regression model. Environ. Health 15 (1), 61.

Quanjer, P.H., et al., 2012. Multi-ethnic reference values for spirometry for the 3-95-yr age range: the global lung function 2012 equations. Eur. Respir. J. 40 (6), 1324-1343.

Rice, M.B., et al., 2016. Lifetime exposure to ambient pollution and lung function in children. Am. J. Respir. Crit. Care Med. 193 (8), 881-888.

Roy, A., et al., 2012. Ambient particulate matter and lung function growth in Chinese 
children. Epidemiology 23 (3), 464-472.

Schultz, E.S., et al., 2012. Traffic-related air pollution and lung function in children at 8 years of age: a birth cohort study. Am. J. Respir. Crit. Care Med. 186 (12), 1286-1291.

Schultz, E.S., et al., 2016. Early-life exposure to traffic-related air pollution and lung function in adolescence. Am. J. Respir. Crit. Care Med. 193 (2), 171-177.

Stern, D.A., et al., 2007. Poor airway function in early infancy and lung function by ag 22 years: a non-selective longitudinal cohort study. Lancet 370 (9589), 758-764.

Tai, A., et al., 2014. The association between childhood asthma and adult chronic obstructive pulmonary disease. Thorax 69 (9), 805-810.
Tsui, H.C., et al., 2018. Lifetime exposure to particulate air pollutants is negatively associated with lung function in non-asthmatic children. Environ. Pollut. 236, 953-961.

Usemann, J., et al., 2017. Inert gas washout: background and application in various lung diseases. Swiss Med. Wkly. 147, w14483.

Vodonos, A., Awad, Y.A., Schwartz, J., 2018. The concentration-response between long term PM2.5 exposure and mortality; a meta-regression approach. Environ. Res. 166, 677-689.

World Health Organization (WHO), 2018. Ambient (outdoor) air quality and health. 30.05.2018, 02.05.2018, Available from. http://www.who.int/news-room/factsheets/detail/ambient-(outdoor)-air-quality-and-health. 